\title{
COMPARISON OF DRAG AND INERTIA COEFFICIENTS FOR A CIRCULAR CYLINDER IN RANDOM WAVES DERIVED FROM DIFFERENT METHODS
}

\author{
Tri Cao Mai ${ }^{1}$, Mayumi Wilms ${ }^{2}$, Arndt Hildebrandt ${ }^{3}$, Torsten Schlurman ${ }^{4}$
}

\section{INTRODUCTION}

Wave load is the most important aspect in designing of offshore structures, i.e. offshore wind turbines (OWT), oil platforms, etc. This has been discussed extensively in previuos studies e.g Sarpkaya \& Isaacson (1981); Sumer et al. (2006); Heideman et al. (1979) and Davies et al. (1990). Generally, estimations of the wave loads are mainly based on the Morison equation (Morison et al., 1950). By applying the Morison approach, the important parameters are the loading coefficients, i.e. the drag and inertia coefficients. There are available methods to estimate these coefficients, i.e.: the leastsquares method with fitting on time domain and/or frequency domain; waveby-wave fitting the method of moments (Isaacson et al., 1991).

The accuracy of methods in estimating the force coefficients $\left(C_{D}\right.$ and $\left.C_{M}\right)$ are discussed in Isaacson (1991). The first approach seems to be the most accurate.

Heideman et al. (1979) and Davies et al. (1990) determined the drag and inertia coefficients in random wave conditions as a function of KeuleganCarpenter number ( $K C=U T / D$, where $U$ is the horizontal velocity, $T$ is the wave period and $\mathrm{D}$ is the cylinder diameter), see Figure 1. The drag coefficient is considerably scatterred at low KC number.

\section{METHODOLOGY}

In this paper available methods are used to estimate the force coefficients. Those are the max-min method and least-squares method (simplified by fit on wave-by-wave basis). According to the method of max-min values of wave kinematics are determined only at the crest, trough and still water level for each individual wave. The least-squares method in time domain is simplified by Davies (1990) by applying a wave-by-wave basis

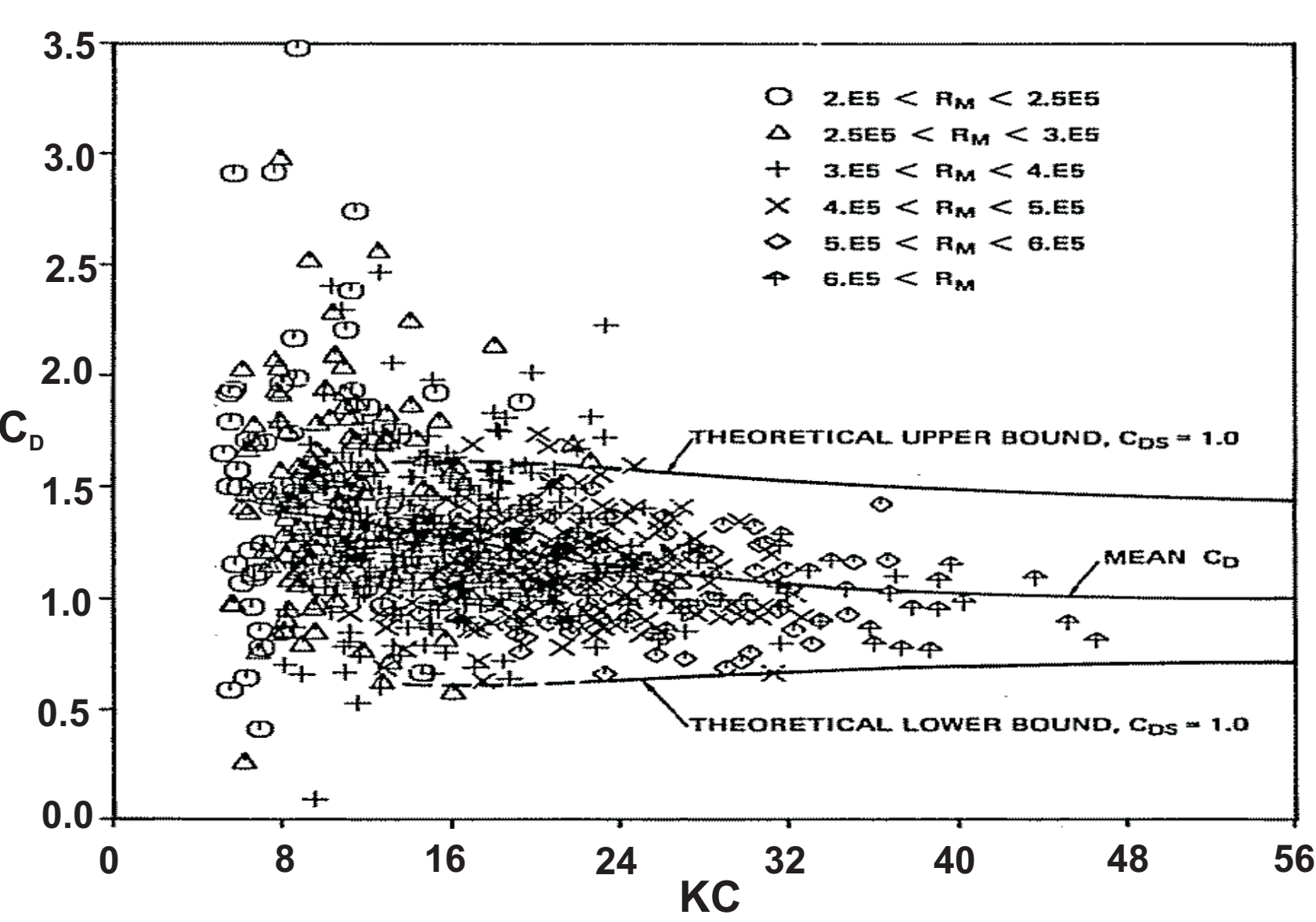

(a) Heideman 1979

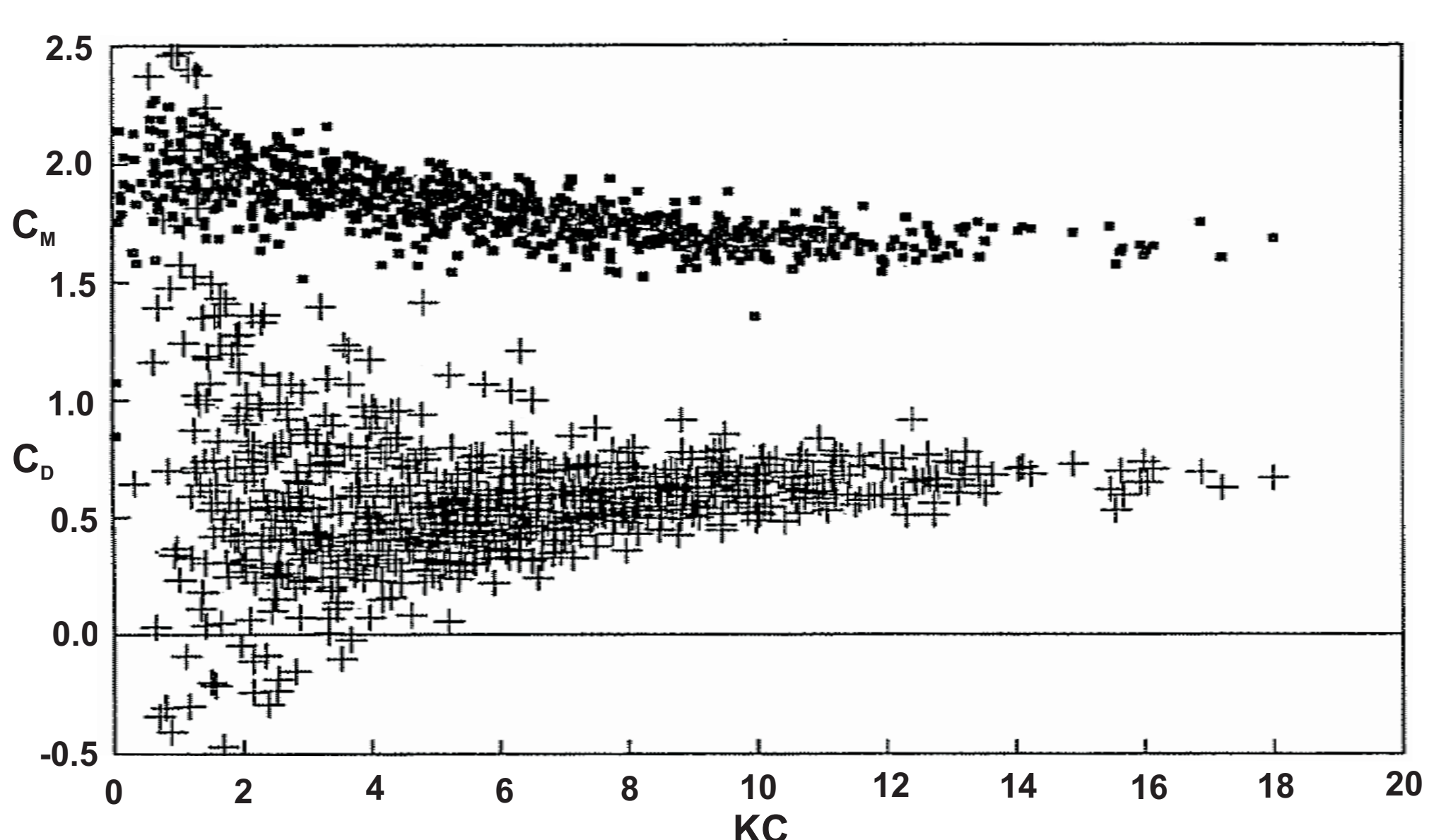

(b) Davies 1990
Figure 1: The correlations of the force coefficients and Keulegen-Carpenter number

\section{STUDY APPROACH}

In this study, a combination of analytical approaches and interpreting results of physical model tests is applied. Series of physical model experiments are conducted by fixing a cylinder with a diameter of $30 \mathrm{~cm}$ in the wave flume of the Franzius-Institute (Germany), see Figure $2 \& 3$. Sets of random waves are applied in combination with varying water depths. For each test pressures around the cylinder induced by waves are measured at different elevations. Measured data are used to estimate the coefficients derived from analytical approaches in combination with different wave theories (Airy, Stokes $2^{\text {nd }}$ and $5^{\text {th }}$ order).
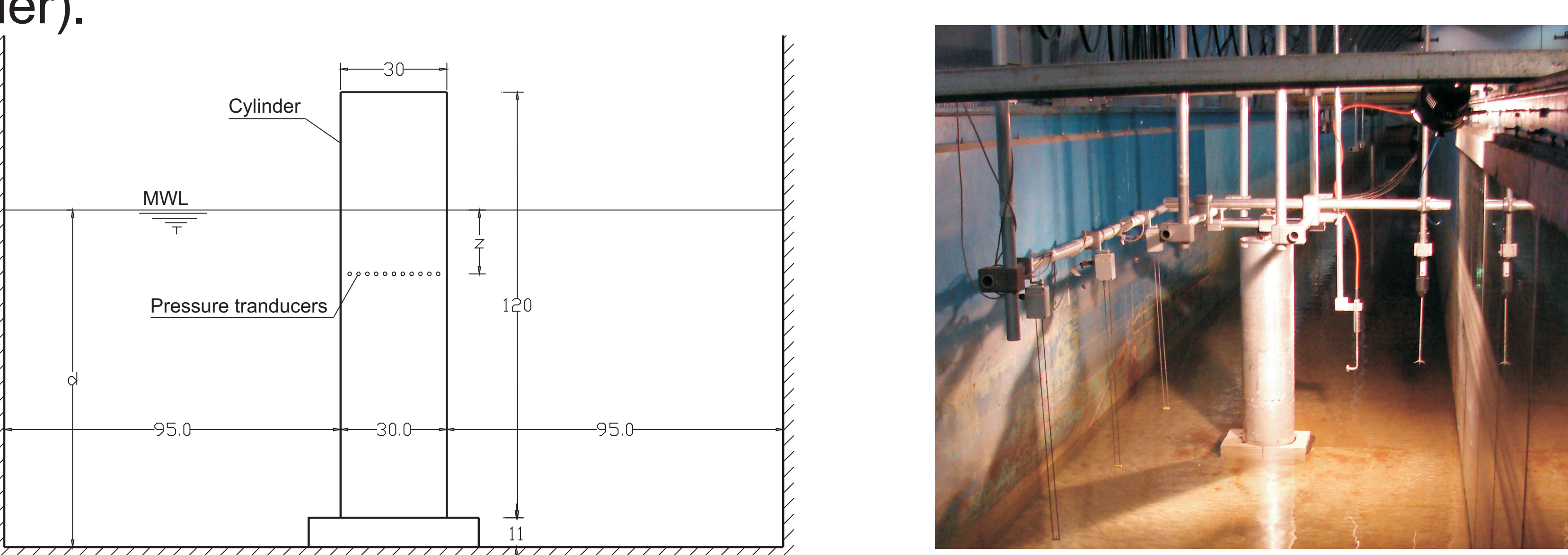

Figure 2: Setting up experiments (units in $\mathrm{cm}$ )

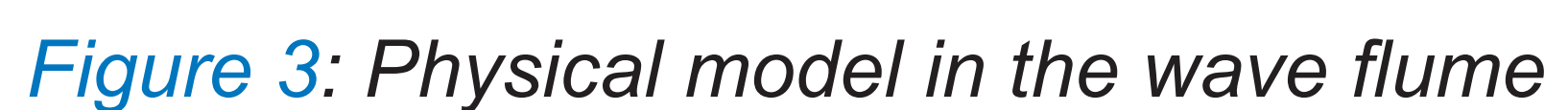

Morison equation: $F(t)=\frac{1}{2} \cdot \rho \cdot C_{D} \cdot D \cdot u(t) \cdot|u(t)|+\frac{\pi}{4} \cdot \rho \cdot C_{M} \cdot D^{2} \cdot \dot{u}(t)$

Least-squares method: $\quad\left\{\begin{array}{l}f_{d} \cdot \sum u^{4}(t)+f_{i} \cdot \sum u(t) \cdot|u(t)| \cdot \dot{u}(t)=\sum u(t) \cdot|u(t)| \cdot F_{m}(t) \quad f_{d}=\frac{1}{2} \cdot \rho \cdot C_{D} \cdot D \\ f_{d}\end{array}\right.$ $\left\{\begin{array}{c}f_{d} \cdot \sum u(t) \cdot|u(t)| \cdot \dot{u}(t)+f_{i} \cdot \sum \dot{u}^{2}(t)=\sum \dot{u}(t) \cdot F_{m}(t) \quad f_{i}=\frac{\pi}{4} \cdot \rho \cdot C_{M} \cdot D^{2} \\ F\left(t_{1}\right)\end{array}\right.$ Max-min method:

$$
C_{D}=\frac{F_{m}\left(t_{1}\right)}{\frac{1}{2} \cdot \rho \cdot D \cdot u\left(t_{1}\right) \cdot\left|u\left(t_{1}\right)\right|}
$$
$F_{m}\left(t_{2}\right)$

\section{SUMMARY OF THE RESULTS}

- Applying different wave theories results in an variation of $\sim 10 \%$ in estimating the wave force coefficients.

- Relations of drag and/or inertia coefficients, and the Reynolds- and/or KC numbers are established. The force coefficients are correlated to the KC number, however the drag coefficient is rather scattered at low KC number (Figure 4). This agrees well with previous studies in Davies (1990), Heideman (1979) and Isaacson (1991)
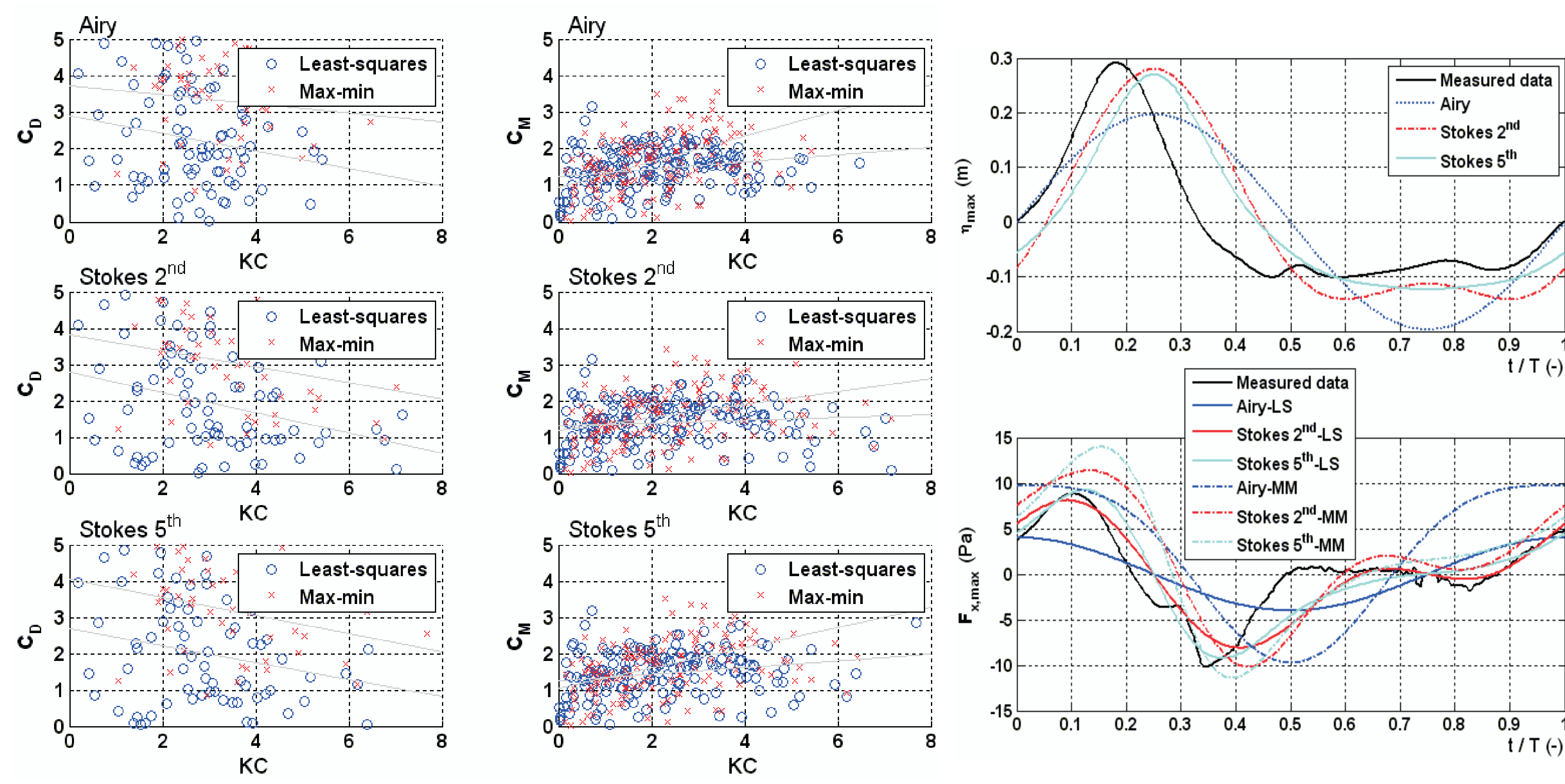

Figure 4: $C_{D}, C_{M} \& K C$-number at level $z=-0.1 m$

Figure 5: Wave surface \& force at $z=-0.1 m$

Table 1: The mean values of $C_{D} \& C_{M}\left(H_{s}=0.2 m\right.$ Table 2: The mean values of $C_{D} \&$
$\left.T_{p}=3.0 \mathrm{~s}, \quad d=0.95 \mathrm{~m}\right)$
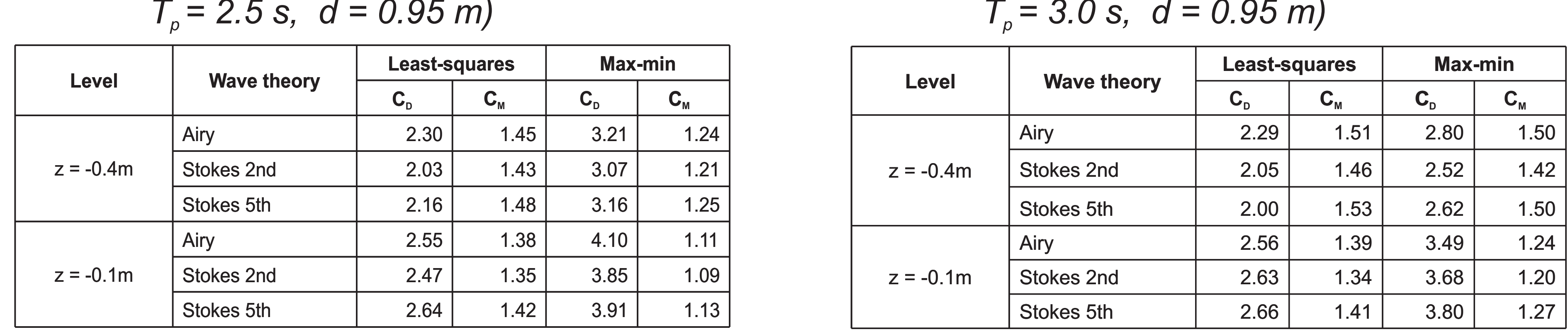

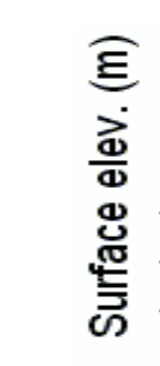

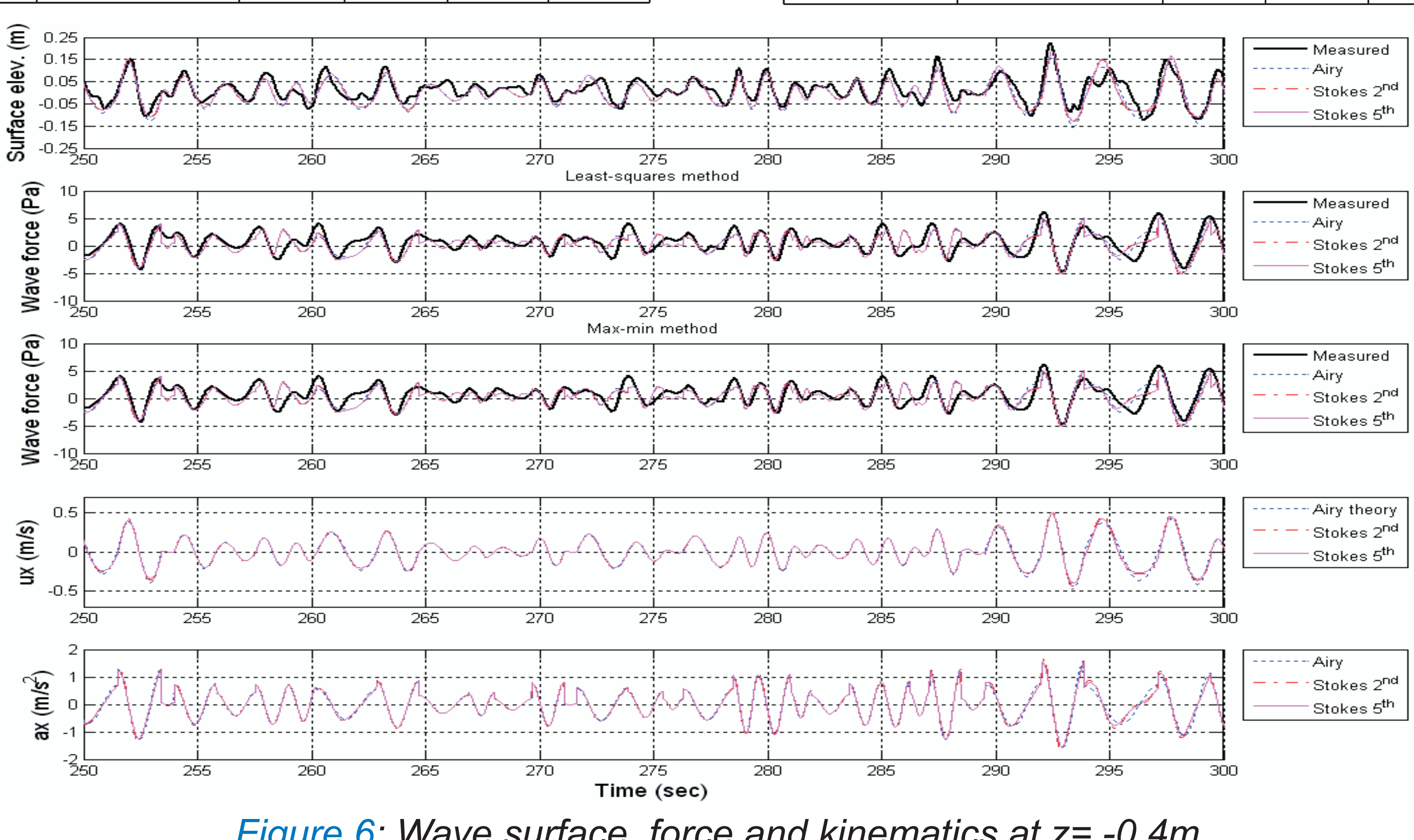

Figure 5 presents the estimated force at a level of $0.1 \mathrm{~m}$ below mean water leve (MWL) on the cylinder. It appears that the estimation of Stokes $5^{\text {th }}$ order agrees well with the measured data.

Table $1 \& 2$ show the mean values of $C_{D}$ and $C_{M}$ at different levels of the cylinder under two wave conditions.

Figure 6 shows the water surface, wave forces and wave kinematics at level of $0.4 \mathrm{~m}$ below MWL for a random wave condition.

\section{MAIN REFERENCES}

Davies, M. J. S., Graham, J. M. R., Bearman, P. W., "In-line forces on fixed cylinders in regular and random waves". In Conf. on

Heideman, J. C., Olsen, O. A. Johansson, P. I., “Local wave force coefficients". Volume IV, 1979.

Henderson A. R Zaaijer. A. B "H "Hdrodynamic Loading on Offshore Wind Turbine Support Structures" Engineering Integrity Society, Volume 25, pp24-31, 2008 .

Iaacson, M., Baldwin, J., Niwinski, C., "Estimation of drag and inertia coefficients from random wave data". Journal Offshore Mechanics and Arctic Engineering, 113 (2), pp. 128-136, 1991

The

作 Sumer, B. M., Fredsøe, J., "Hydrodynamics around cylindrical structures" (Revised Edition). World Scientific Publishing Co. Pte. Ltd., Denmark, 2006.
M.Sc.,mai@fi.uni-hannover.de (corr. author) Dipl.-Ing.,wilms@fi.uni-hannover.de Dipl.-Ing., hildebrandt@fi.uni-hannover.de Prof. \& Director, schlurmann@fi.uni-hannover.de
Franzius-Institute for Hydraulic, Waterways and Coastal Engineering Leibniz University Hannover. Nienburger Str 4, 30167 Hannover, Germany. 